\title{
JaCQUES LACAN E A CLÍNICA DO CONSUMO
}

Márcia Rosa*

\section{RESUMO}

O texto destaca e percorre os principais momentos nos quais Jacques Lacan se deteve sobre a questão do consumo e, ao fazê-lo, desdobrou três pontos. Inicialmente, o consumo articula-se à ética e à constatação da impossibilidade de pensá-lo apenas com a noção de valor de uso; aquelas de valor de gozo e valor de desejo tornam-se necessárias. A seguir, a associação do consumo ao campo pulsional, especialmente ao objeto oral e às fantasias de devoração, evidencia o deslizamento do "consumismo" à "consumição", que leva o sujeito da posição de consumidor à de objeto consumido. Finalmente, o consumo é tratado nos últimos textos de Lacan através de uma pequena mutação no Discurso do Mestre que faz surgir o Discurso do Capitalista.

Palavras-chave: consumo, ética, pulsão, discurso do capitalista.

\section{Abstract}

JACQUES LACAN AND THE CONSUMPTION CLINIC

The text highlights and discusses the key moments in which Jacques Lacan stood on the issue of consumption and, by doing so, deploys three points. Initially, consumption is articulated to ethics and to the impossibility of thinking it only through the notion of value; the notions of jouissance and desire value become necessary. Next, the association of consumption to trieb, especially to the oral object and to devouring fantasies, shows the change of "consumerism" to "consumption" that leads the subject from a position of consumer to one of an object to be consumed. Finally, consumption is treated in Lacan's last texts through a small mutation in the Master's Discourse that gives rise to the Capitalist Discourse.

Keywords: consumption, ethic, trieb, capitalist discourse.

* Psicóloga; Psicanalista; Membro da Escola Brasileira de Psicanálise e da Associação Mundial de Psicanálise; Doutora em Literatura Comparada pela Universidade Federal de Minas Gerais (UFMG); Pós-Doutora em Teoria Psicanalítica pela Universidade Federal do Rio de Janeiro (UFRJ); Professora Adjunta do Departamento de Psicologia da Universidade Federal de Minas Gerais (UFMG). 
No final do ano de 1974, ao fazer sua terceira conferência na cidade de Roma, Jacques Lacan ([1974] 1980) provocativamente interrogou se a psicanálise seria um sintoma. Dizendo, logo a seguir, não formular perguntas cuja resposta não soubesse de antemão, ele definiu o sintoma como algo que vem do real. Para explicá-lo, disse que o sintoma apresenta-se como um peixinho cuja boca voraz não se fecha se não se lhe põe sentido sobre os dentes. Então, de duas uma: ou ele cresce e multiplica, ou ele morre. Diante das duas possibilidades, melhor seria que ele morresse, afirma.

Não sem mencionar Freud ([1916-1917] 1974) nas suas "Conferências introdutórias sobre a psicanálise", Lacan observou que "o sentido do sintoma não é aquele com que se o alimenta para a sua proliferação ou extinção, o sentido do sintoma é o real" (Lacan, [1974] 1980: 168), real entendido como aquilo que "impede que as coisas andem no sentido em que dão conta de si mesmas de maneira satisfatória” (Lacan, [1974] 1980: 168). Em resposta à provocação inicial, propôs que o sentido do sintoma depende do futuro do real, ou seja, do êxito da psicanálise. Se o que se pede da psicanálise é que nos libere do real e do sintoma, se ela triunfar nisso não teremos muito a esperar senão um retorno da "verdadeira religião” (Lacan, [1974] 1980: 168). Caso seja bem-sucedida, ela própria se extinguirá, restando apenas como "um sintoma esquecido" (Lacan, [1974] 1980: 169). Portanto, a conclusão de Lacan é de que tudo depende da insistência do real, e para que ele insista é preciso que a psicanálise fracasse no que se lhe pede. Na sua avaliação, ela está no bom caminho e tem grandes probabilidades de continuar sendo um sintoma.

Depois de ter localizado a psicanálise em relação ao sentido e à religião, o autor do texto "A terceira" (Lacan, [1974] 1980) interrogou a sua relação à ciência e, também aí, destacou a importância do sintoma. Ao observar que para a maioria das pessoas a ciência se reduz àquilo que ela oferece, isto é, se reduz aos "artefatos de consumo: a televisão, a viagem à lua, e mais uma vez a viagem à lua” (Lacan, [1974] 1980: 186), o psicanalista enfatizou que o futuro da psicanálise depende do que vai ocorrer com esse real, isto é, depende "de que os gadgets se imponham verdadeiramente" (Lacan, [1974] 1980: 186). Quanto a isso, continua, "devo dizer que me parece pouco provável. Não conseguiremos verdadeiramente que o gadget não seja um sintoma, pois pelo momento o é muito evidentemente" (Lacan, [1974] 1980: 186).

Definidos como objetos fabricados pela ciência, a presença marcante dos gadgets (uma gíria eletrônica que se refere a objetos de uso prático no cotidiano, tal como celulares, smartphones, etc.) na nossa contemporaneidade abre um debate sobre o consumo, sobre os artefatos de consumo, se quisermos manter o termo com 
o qual o psicanalista francês se refere a eles. Em vista desses comentários feitos em meados dos anos setenta, interessa-nos rastrear o modo como Lacan trata a questão do consumo, cujo tema apresenta-se desde os primeiros momentos do seu ensino. Ao fazê-lo, três pontos são desdobrados: inicialmente o consumo é articulado à ética, em seguida ao campo pulsional, especialmente ao objeto oral e às fantasias de devoração, e, finalmente, ao discurso do capitalista.

\section{Parte um: o consumo e a ética}

Constatamos que o tratamento da questão do consumo feito por Lacan ([1959-1960] 1988) no Seminário 7-A ética da psicanálise traz operadores interessantes para o debate, a saber: a estrutura da linguagem e sua cadeia de significantes, os bens como algo do qual o sujeito pode dispor ou se privar e a teoria dos valores: valor de tempo, valor de uso, valor de gozo, valor de desejo.

\section{A) ADÃO, EVA E O CASACO DE VISON}

Para começar, uma pergunta: afinal, como tem início essa estória de consumo? $\mathrm{E}$, para tratar as origens, nada melhor do que as fábulas. Temos, pois, essa que põe em cena Adão, Eva e a dimensão significante. "Eis, então, Adão, e eis esses famosos pelos de uma Eva que ansiamos estarem à altura da beleza que esse primeiro gesto evoca”, comenta Jacques Lacan com a ironia que lhe é peculiar. Pois bem, "Adão arranca um pelo daquela que lhe é oferecida como cônjuge, esperada por toda a eternidade, e, no dia seguinte, ela volta para ele - com um casaco de vison nos ombros" (Lacan, [1959-1960] 1988: 277).

Com esse comentário picante, Lacan introduz a questão dos bens. Ele observa que na medida em que a realidade é constituída com o prazer, interessam as relações do homem com os objetos de sua produção, uma vez que eles serão objetos de suas necessidades, mas também de seus desejos, e é patente que há uma distância entre a organização das necessidades e dos desejos (Lacan, [1959-1960] 1988). Para ele, o problema dos bens se coloca no interior do que é a estrutura de linguagem e, nesse sentido, os bens serão objetos de discursos diversos. Assim, um pedaço de pano, dado que com ele se pode fazer uma roupa, é um valor de uso, um objeto do campo do útil, no entanto suscita comentários diversos: um analista diria que ele mostra e esconde ao mesmo tempo, sem que se possa saber "se o que se trata de fazer com este falo-pano é revelar ou escamotear" (Lacan, [1959-1960] 
1988: 276), um marxista observaria que o fato de o homem ter menos pelos do que alguns animais leva à criação da indústria, enquanto para os linguistas seria "como significante que o que quer que seja se articula, nem que seja uma cadeia de pelos" (Lacan, [1959-1960] 1988: 277).

O homem fabrica algo que pode estar ou não em "uma relação de encobrimento em relação a seu próprio corpo, mas que vai correr o mundo independentemente como pano, que vai circular" (Lacan, [1959-1960] 1988: 278). Inserido no tempo, esse pano diferencia-se de qualquer produção natural; uma vez fabricado, ele está sujeito à moda, à antiguidade, à novidade. Ele estará lá, se precisarmos dele ou não. Se as necessidades do homem se alojarem no útil, configurando um valor de uso, a lei que organizará a função dos bens rezará "o máximo de utilidade para a maioria” (Lacan, [1959-1960] 1988: 279). Nesse caso, o pano terá sido feito para que o maior número possível de sujeitos introduzam a cabeça e os ombros nos furos que se fizerem nele. Só que as coisas começam a funcionar de outro modo quanto aos objetos: "há no início outra coisa além de seu valor de uso - há sua utilização de gozo" (Lacan, [1959-1960] 1988: 279), seu valor de gozo.

Começa a se delinear o problema dos bens e de sua função: como são criados os bens, dado que fornecem matéria para uma repartição? Uma definição analítica do que seriam os bens se esboça: o bem, diz Lacan, não está no nível do uso do pano, está no nível disso - o sujeito pode dispor dele, assim como pode dispor de si mesmo. "Freud já nos abrira esse caminho: dispor de seus bens é ter o direito de privar os outros deles. Agora, se o sujeito pode dispor de seus bens, pode também defendê-los, isto é, pode proibir a si mesmo de gozar deles" (Lacan, [1959-1960] 1988: 279-280).

Constatamos que o tratamento da questão do consumo pela ética da psicanálise leva a uma proposta de que "o valor de uma coisa é a sua desejabilidade - tratase de saber se ela é digna de ser desejada, se é desejável que a desejemos” (Lacan, [1959-1960] 1988: 24). Sobre esse valor de desejo o psicanalista comenta termos entrado com ele em uma espécie de lista que se poderia comparar a "uma loja de roupa usada, onde se empilham as diversas formas de veredicto que no decorrer dos tempos, e ainda hoje, dominaram por sua diversidade [...] as aspiraçôes dos homens" (Lacan, [1959-1960] 1988: 24). Portanto, o que é desejável se insere no tempo, está sujeito aos usos e aos modos de satisfação pulsional. Com isso, ao tratar da produção, circulação e do consumo dos bens, a teoria psicanalítica introduz dois novos operadores, o gozo e o desejo, e eles dão ao tratamento psicanalítico do consumo um viés clínico que o especifica em relação a outras leituras, aquelas mais sociológicas, por exemplo. 


\section{B) AS CAIXAS REGISTRADORAS E A CIFRAGEM DO GOZO}

Que a relação do sujeito com os objetos de sua produção, e de seu consumo, esteja marcada pelo significante leva Lacan a extrair do campo do cinema, de um filme de Jules Dassin, "Nunca aos domingos", um outro ângulo a ser considerado quando se trata do consumo. Ele destaca na trama do filme uma cena em princípio secundária: o personagem, que é apresentado pela imediaticidade de seus sentimentos, em alguns momentos mostra o seu excesso de entusiasmo e satisfação bebendo um copo e depois quebrando-o. "Cada vez que um desses estrondos se produz, vemos a caixa registradora se agitar freneticamente" (Lacan, [1959-1960] 1988: 380-381). Para o psicanalista, essa caixa define muito bem a estrutura com a qual lidamos, uma vez que para que o campo do desejo exista é necessário que o que ocorre de real seja contabilizado em algum lugar. Uma vez que a culpa habita o campo do desejo, surgem "cadeias de contabilidade permanente" (Lacan, [1959-1960] 1988: 380-381), contabiliza-se o menos, as faltas, as privações, mas também o mais, os excessos.

Com Eva, Lacan introduzira ironicamente uma cadeia de pelos e, agora, mostra que eles são contáveis. Logo, a contabilidade, a cifra, a cifração do real, que em alguns casos serve à falicização do gozo, estão em jogo aí. Se o caçador antigo contabilizava entalhes, no mundo contemporâneo temos aparelhos, engenhocas eletrônicas que registram os excessos e os contabilizam. Essa presença da máquina e dos seus registros emerge na fala de uma analisante quando, ao indagar na sessão o seu consumo desenfreado e o seu endividamento, se dá conta de que as suas dívidas ela as contraíra nessas máquinas de Caixa Eletrônico, 24 horas em funcionamento self-service, tal como um pronto-socorro. Um detalhe lhe chama a atenção: o barulhinho da máquina. Esse barulhinho não era sem importância na dívida contraída com (ou a partir de) uma máquina. Algo da maquinaria significante, da cifração do real, não deixava de estar em jogo aí. Já uma outra analisante diz, em um dos momentos em que se queixa sobre o lugar de pouca importância que sempre teve no desejo de sua mãe, que ela, a sua mãe, tem uma coleção de mais de 80 pares de sapatos. Pelo que parece, o gozo materno encontrou no que poderíamos denominar consumismo um modo de cifração, de (se) fazer cifra, isto é, um modo de (se) contabilizar. Talvez já não se façam mães fálicas como antigamente! Obviamente, alguns giros seriam necessários para que esse modo de gozo e de cifração viesse a vacilar e a se constituir em um sintoma analítico. 


\section{C) UMA SATISFAÇÃO QUE NÃO PEDE NADA A NINGUÉM}

Ao tomar a forma de um ato de colecionar, o consumo pode mostrar-se associado não apenas a uma cifração do real, a uma contabilização, mas também a um movimento de sublimação. Com isso, chegamos ao que parece estar no pano de fundo da discussão sobre o consumo e a ética da psicanálise proposta por Lacan no início dos anos 60, a saber: a sublimação. Nas suas elaboraçōes, ele se refere ao encontro com um colecionador e com a sua coleção de caixas de fósforo. Ao dizer ser, ele mesmo, um pouco colecionador e evocar as coleções de Freud, tributárias do fascínio que exercia sobre ele a civilização egípcia, Lacan estabelece uma distinção entre o que denomina "objeto como fundamento da coleção" (Lacan, [1959-1960] 1988: 142) e o sentido daquilo que denomina objeto na análise: "na análise o objeto é um ponto de fixação imaginário dando, em qualquer registro que seja, satisfação a uma pulsão. O objeto de coleção é outra coisa completamente diferente" (Lacan, [1959-1960] 1988: 142).

No caso mencionado, o surpreendente na coleção de caixas de fósforo de Jacques Prévert é que o ajuntamento de caixas de fósforo vazias - esse o ponto essencial - tornava evidente que "uma caixa de fósforos não é de modo algum simplesmente um objeto com uma certa utilidade, mas pode ser uma Coisa, uma coisa com sua coerência de ser" (Lacan, [1959-1960] 1988: 143). Ao apresentá-la como "uma forma vagabunda da gaveta" (Lacan, [1959-1960] 1988: 144), Lacan mostra que nessa coleção a gaveta apresentava-se liberada e não mais em sua "amplitude ventral, cômoda" (Lacan, [1959-1960] 1988: 144), revelando a Coisa para além do objeto. Essa Coisa, revelada para além do objeto, colocar-nos-ia diante de uma das formas da sublimação: "se é uma satisfação, pelo menos nesse caso, é uma satisfação que não pede nada a ninguém” (Lacan, [1959-1960] 1988: 144).

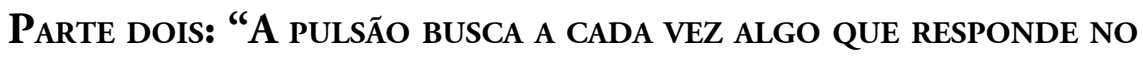 OUTRo"}

Depois dessa primeira localização do consumo em uma dimensão ética, creio ser importante relançar a questão mais além da determinação do sujeito pelo significante. Trata-se, pois, de interrogar o campo pulsional em jogo no consumo. Para tal privilegiaremos as articulações entre o consumo e o campo da pulsão e do objeto oral.

Ao retomar o texto "Os instintos e suas vicissitudes" (Freud, [1915] 1974), Lacan indica que Freud escreve a atividade e a passividade das pulsões com o 
recurso das vozes gramaticais. Com as mudanças de posição, através das quais o sujeito pratica ou recebe a ação do verbo, temos as vozes ativa, passiva e reflexiva. Assim, a pulsão oral seria formulada nos termos: devorar, ser devorado, devorarse. Não muda o objeto, não muda o outro, o que muda é o ponto no qual incide a ação do verbo, de tal modo que em um dos giros o sujeito é reduzido à posição de objeto. Lacan introduzirá uma pequena nuança nessa gramática pulsional freudiana. Para ele há sempre uma atividade em jogo na pulsão; portanto, ao invés do "se devorar", "se consumir", ele propõe o "se fazer", "se fazer devorar", "se fazer consumir". É nesse "se fazer" que a atividade da pulsão se concentra, indica ele (Lacan, [1964] 1988).

\section{A) "DECIFRA-ME OU TE DEVORO"}

O "se fazer papar" nos conduz ao campo fantasmático e às fantasias de devoração nas quais a pulsão oral lança suas raízes no terreno do masoquismo. Se a pulsão oral é "se fazer sugar", surgirão aí não apenas a figura do lactente em sua "voracidade divina” em relação ao valor agalmático do objeto que é o seio ("objeto chapado, que chupa o quê? - o organismo da mãe"), assim como a figura do vampiro, que deixa o sujeito na posição de "se fazer chupar" (Lacan, [1964] 1988). O ponto importante a ser realçado é que a pulsão "está encarregada de ir buscar algo que, de cada vez, responde no Outro" (Lacan, [1964] 1988: 185). Ou seja, não há aí manifestação de um declínio, inconsistência, ou mesmo inexistência do Outro. Pelo contrário, o "se fazer devorar" faz existir e dá consistência ao Outro. E não se trata de um Outro qualquer, o sujeito constrói o seu grande Outro sob medida, e ele surge aí com essa face medonha de Outro devorador.

"Decifra-me, ou te devoro", diz a Esfinge. Com seu imperativo, ela se torna uma dessas figuras do pesadelo, presença angustiante do gozo do Outro. No entanto, por outro lado, ela é também uma figura questionadora. Com a sua pergunta ("que animal é este que anda com quatro pés pela manhã, dois ao meio-dia e três à noite?”) ela formula uma demanda. "Trata-se aí de um significante que se propõe, ele mesmo, como opaco, constituindo a posição do enigma como tal. Temos aí a forma mais primordial da demanda do Outro" (Lacan, [1962-1963] 2005: 73). Todavia, a demanda pode também se manifestar como uma demanda ao Outro. Tal é o caso dessa jovem mulher que vai ao analista para se queixar de um mal-estar vago e inespecífico, consigo mesma e com o outro. Para a analista, parecia evidente que ela a consultava devido à sua obesidade, ao seu excesso de peso, no entanto isso demorava a ser tomado como um sintoma. "Gorda" havia 
se transformado para esse sujeito em um modo de ser que não suscitava perguntas. Com o trabalho da análise, vai se evidenciar a posição de objeto oral na qual ela se oferecia ao Outro: ela estava sempre lá onde a demandavam, bastava que o outro pedisse e ela se fatigava para pôr em cena a sua personagem: boa mãe, boa esposa, boa trabalhadora. Se a demanda, no nível inconsciente, relaciona-se com a inconsistência do Outro, nesse caso a inconsistência não aparecia, uma vez que, antes mesmo que a demanda aparecesse, o sujeito se oferecia, se antecipava em uma espécie de generosidade oral, traço que Karl Abraham ([1924] 1970) considerou característico do que denomina caráter oral. Fato é que, quando era impossível para esse sujeito responder às demandas e manter a sua personagem, manifestava-se um ponto de gozo específico: a bulimia. No desenrolar do tratamento desse caso, relatado por Diana Rabinovich (1989), observa-se como o trabalho da análise opera um deslocamento na ganância de gozo que levava o sujeito do consumo excessivo de alimentos a uma posição na qual ela própria era consumida, na qual ela se oferecia como pasto à devoração do Outro. No desenrolar do tratamento, à medida que o sujeito perde em peso, o Outro perde em consistência.

\section{B) A FASE ORAL E O CANIBALISMO}

Ao tomar, no Seminário 8 - A transferência, a pulsão oral na sua dimensão de demanda dirigida ao Outro, Lacan ([1960-1961] 1992) evidencia que há uma hiância no confronto entre a demanda do sujeito de ser alimentado e a demanda, no campo do Outro, de que ele se deixe alimentar. É o que se mostra nos casos de anorexia mental. Consoante Eric Bidaud (1998), ao recusar o alimento "a anorética está retida na ilusão de que nenhum outro é susceptível de recusá-lo a ela" (Bidaud, 1998: 75). Para Lacan, a recusa anorética em satisfazer a demanda seria uma tentativa de salvaguardar o desejo. No entanto, a isso ele acrescenta que "a demanda oral tem um outro sentido além da satisfação da fome. Ela é demanda sexual. Ela é, em seu fundo [...] canibalismo, e o canibalismo tem um sentido sexual" (Lacan, [1960-1961] 1992: 202). O horizonte do canibalismo caracteriza a fase oral como aquilo que ela é na teoria psicanalítica, na medida em que o sujeito primitivo tem que se alimentar do corpo daquele que o alimenta. Nesse sentido, "a vida é, no fundo, assimilação devoradora como tal” (Lacan, [1960-1961] 1992: 205), diz ele.

Ao tratar a demanda oral no campo da transferência, Lacan recomenda aos analistas "prudência quanto à interpretação no nível do registro oral" (Lacan, [19601961] 1992: 203), de modo a que se preserve aí o campo da fala e a possibilidade de sempre reencontrar o desejo. Uma vez que a boca que tem fome se exprime 
por uma cadeia significante, em frente ao alimento ela pode dizer "esse não", pode negar, afastar, pode dizer "eu gosto disso e não de outra coisa", fazendo explodir a especificidade do desejo. Desse modo, o psicanalista manifesta as suas reservas quanto à compreensão da demanda, já que o importante é aquilo que está para além dela: essa margem de incompreensão é a mesma do desejo. Ao ceder nesse ponto, com um analisante obsessivo, por exemplo, o analista pode se deparar com um mecanismo pelo qual "ele quer fazê-los comer seu próprio ser - uma merda" (Lacan, [1960-1961] 1992: 207). Percebe-se, pois, que o analista pode ser chamado a fazer as vezes desse Outro consumidor, devorador.

\section{C) $\grave{A}$ MARGEM DO DESEJO, A GOELA ABERTA DA VIDA}

"Na fase oral, é o tema do devoramento que está situado à margem do desejo, é a presença da goela aberta da vida" (Lacan, [1960-1961] 1992: 205). Portanto, o "se fazer devorar", "se fazer consumir" situa-se à margem do desejo, tem a estrutura da fantasia sadomasoquista na qual se espera um sofrimento do Outro. Assim, a Esfinge, o Pequeno Sugador, o Vampiro, o Canibal e, mesmo, a Generosa seriam modos de apresentação dessa lógica fantasmática em jogo no "se fazer devorar". Com um tom de ironia que, como já dito, acompanha toda a elaboração do tema, Lacan acrescenta duas outras figuras à série de devoradores/devorados ou de consumidores/consumidos: o louva-a-deus fêmea e as fantasias de comunhão de Baltasar Gracián.

Ao tomar na espécie animal o que entende como um modelo para abordar o canibalismo oral, o psicanalista francês mostra como o louva-a-deus macho perde literalmente a cabeça no ato de copulação com a louva-a-deus fêmea. Nesse ato assombroso, a extremidade cefálica do macho é devorada; é isso que a fêmea ama, ela goza às expensas do outro. Já com Baltasar Gracián e suas fantasias de comunhão, observa-se uma transição da fome ao erotismo. Ao evocar os pecados originais (e, salvo engano, a gula está entre eles), Lacan mostra como "o sujeito vem se situar no cardápio do canibalismo que [...] nunca está ausente de qualquer fantasia de comunhão" (Lacan, [1960-1961] 1992: 211). Chega-se, então, a Gracián e ao seu tratado sobre a comunhão, no qual ele revela algo raramente confessado: "as delícias do consumo do corpo de Cristo são ali detalhadas, e pedem-nos que nos detenhamos naquela bochecha excelente, naquele braço delicioso" (Lacan, [1960-1961] 1992: 216). Dispenso-os da continuação, na qual "a concupiscência espiritual se prolonga” (Lacan, [1960-1961] 1992: 216), assinala Lacan, indicando aí a presença do campo da identificação oral. 


\section{Parte Três: o ÚtIL, o gOZO E O Discurso do CAPITAlista}

Em 1972, no Seminário 20 - Mais, ainda, Lacan ([1972-1973] 1982) diz ter encontrado no campo jurídico um termo que reúne em uma palavra a diferença entre o útil e o gozo, indicada no Seminário 7 - A ética da psicanálise (Lacan, [1959-1960] 1988). O usufruto quer dizer que "podemos gozar de nossos meios, mas não devemos enxovalhá-los” (Lacan, [1972-1973] 1982: 11). Pode-se, pois, fruir de uma herança, com a condição de não usá-la demais. Nesse sentido, em face ao útil, "o gozo é aquilo que não serve para nada" (Lacan, [1972-1973] 1982: 11), e o modo de reparti-lo, de distribuí-lo, faz a essência do Direito. Todavia, continua, se há um direito-ao-gozo, ele não é um dever. "Nada força ninguém a gozar, senão o supereu. O supereu é o imperativo do gozo - Goza! É aí mesmo que se acha o ponto giratório que o discurso analítico interroga" (Lacan, [19721973] 1982: 11).

Nos anos 70, a questão do valor de gozo se refere à vertente mais-de-gozar do objeto e a questão da repartição dos bens introduz a problemática da justiça distributiva e do declínio radical da função do mestre, declínio já assinalado pelo autor do Seminário 7 - A ética da psicanálise (Lacan, [1959-1960] 1988), em benefício do Discurso do Capitalista.

\section{A) O UTILITARISMO E A SUA TEORIA DAS FICÇÕES}

Para Lacan, a psicanálise não é imune ao deslizamento que ocorre no curso dos tempos, deslizamento que leva do mestre antigo e sua ética fundada nos ideais ao utilitarista e sua moral calcada no valor de uso dos objetos, moral emergente no início do século XIX. Ele se apressa em dizer que de Aristóteles a Jeremy Bentham não se trata exatamente de um progresso, mas de diferentes modos de interrogar e, mesmo, de contornar o real. Para os utilitaristas, o mercado dos objetos se constitui a partir de seu valor de uso; dizem eles que "quando lidamos com algo que pode ser trocado com nossos semelhantes, a regra é sua utilidade não para nós, mas a sua utilidade para todos e para o maior número" (Lacan, [1960-1961] 1992: 240). Uma vez inserido em um mundo socializado, mundo da conformidade, coerente com uma organização universal do discurso, esse mercado de objetos, em seu valor de uso e de troca, precisará constituir uma teoria das ficções, algo que permita ir além do objeto em seu estatuto natural e que o estabeleça como objeto de um acordo comum.

Em face disso, o psicanalista não pode senão objetar que, para a psicanálise, “o objeto [...] não é de modo algum apreendido, transmissível, cambiável. Ele está 
no horizonte daquilo em torno do qual gravitam as nossas fantasias. E, no entanto, é com isso que devemos fazer objetos que, por seu lado, sejam cambiáveis" (Lacan, [1960-1961] 1992: 240). Se o objeto, tal como insiste o psicanalista, "deve ser localizado no ponto mais radical onde se coloca a questão do sujeito quanto à sua relação com o significante" (Lacan, [1960-1961] 1992: 240), como ficará isso ali onde ocorre, juntamente ao declínio do mestre, um declínio da função do significante? No correr dos tempos observa-se que esse declínio é concomitante à construção de uma teoria das ficçôes. Ela nos serviria? Em que e de que modo nos serviria? Se com o mestre antigo toda a exploração da ética incidia sobre o domínio do ideal, Lacan deixa a via aberta pelo significante-mestre para seguir com Freud quando ele articula a questão ética interrogando a relação do sujeito ao real. E, aí, o utilitarismo interessará à psicanálise, uma vez que ao tomar as ficçōes não como enganosas e ilusórias, mas em sua função simbólica, ele as oporá ao real. Portanto, para situar o bem e a sua circulação será preciso interrogar as relações da linguagem com o real.

Com a teoria das ficções, que Lacan sempre comenta recolocando no horizonte as formulações de Jeremy Bentham, é o registro do simbólico que é introduzido, ou seja, a verdade em seu estatuto de ficção (Lacan, [1959-1960] 1988). E as ficções utilitaristas organizariam o desejo tal como as fórmulas da fantasia, indagamos? Um outro ponto a considerar: essa regulação pela via das ficções teria, de algum modo, dispensado o recurso ao significante-mestre que é o Nome-do-Pai? Se for esse o caso, introduz-se uma espécie de desabonamento do inconsciente que pode deixar o sujeito à mercê de um imperativo que diz: compre! É onde o mestre antigo cederá seu lugar ao mestre contemporâneo: o capitalista!

\section{B) O DisCURSO DO CAPITALISTA}

Tal como já assinalado, o objeto não está fora do tempo, ele não é hoje o que era na época de Aristóteles e nem mesmo na época do utilitarismo. Isso ocorre na medida em que "o objeto é função dos discursos em ação, é função dos discursos que definem a civilização" (Soler, 1998: 167). Posto isso, resta constatar que a civilização contemporânea "é a civilização da ciência e dos objetos que ela gera" (Soler, 1998: 167). Assim, em 1970, no Seminário 17 - O avesso da psicanálise, Lacan ([1969-1970] 1992) menciona uma "mutação capital [...] que confere ao Discurso do Mestre seu estilo capitalista” (Lacan, [1969-1970] 1992: 160). Esse estilo, tributário de uma pequena inversão entre o significante e o sujeito, será suficiente para constituir o que ele denominará, em Televisão, Discurso do Capi- 
talista. Essa "pequena inversão será suficiente para que isso ande como se estivesse sobre rodas, isso não tem como andar melhor, mas desse modo isso anda rápido demais, isso se consome, isso se consome tão bem que isso se consuma" (Lacan, [1972] 1978: 48), afirma a conferência em Milão, Du discours psychanalytique, na qual Lacan faz a escrita do Discurso do Capitalista:

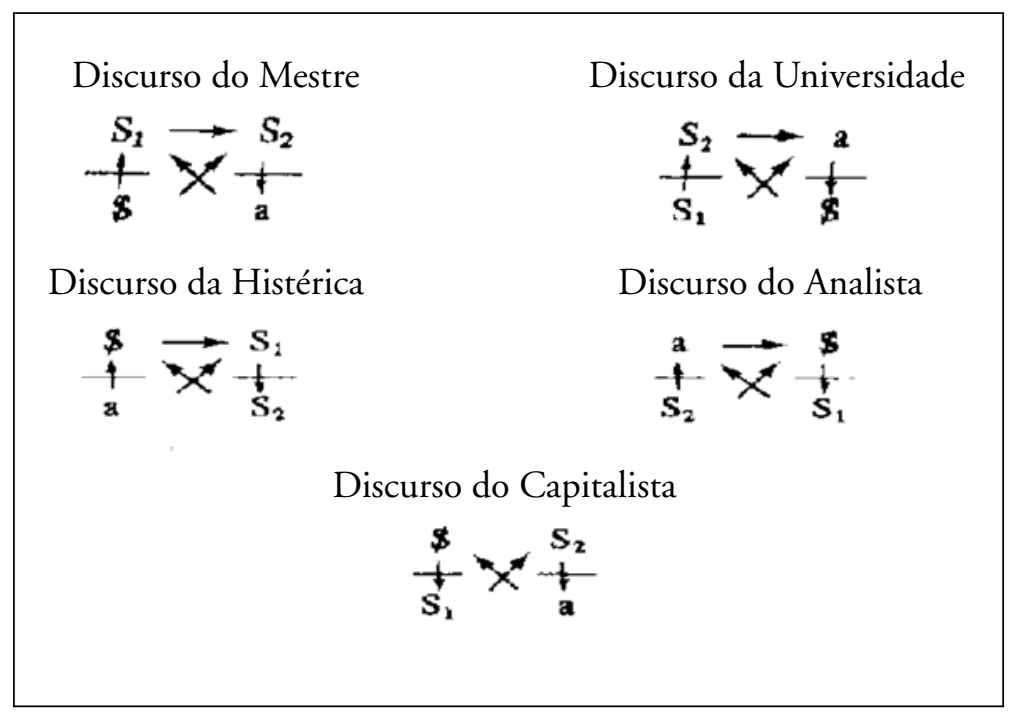

No Discurso do Capitalista, os gadgets, as quinquilharias, os objetos mais-degozar $(a)$ vêm no lugar da produção e, com um frágil anteparo da lógica significante $\left(S_{1} \rightarrow S_{2}\right)$, deixam o sujeito à mercê dos objetos $(X \leftarrow a)$. Se antes falávamos em um objeto oral, passível de deglutição, de assimilação, de consumição, essas novas apresentaçôes do objeto podem deixar o sujeito atordoado. É o caso de uma mulher de origem rural que, tendo ganho um telefone celular, diz à sua filha de pouco mais de dois anos que ela acabara de ganhar uma irmãzinha. Ato seguinte: ela para de fumar, de outro modo como alimentar o celular com cartôes telefônicos! O que se percebe é que, atordoada, ela resolvera adotar aquele pequeno aparelho: o celular!

Ali onde o Discurso do Capitalista prevalece, isso anda como se estivesse sobre rodas, ou seja, anda rápido demais e, desse modo, "isso se consome, isso se consome tão bem que isso se consuma” (Lacan, [1972] 1978: 48). A língua portuguesa, tal como apresentada pelo Dicionário Aurélio, torna-o evidente na medida em que os termos "consumismo" e "consumição" são bastante próximos. No entanto, se o primeiro nos aponta um sistema que favorece o consumo exagerado e indica uma 
tendência a comprar exageradamente, é no segundo termo que o modo de gozo presente nessa tendência ou impulso se explicita: "consumição" indica o ato de consumir(-se), o efeito de consumir, uma mortificação. Indo além dos substantivos, o verbo "consumir", do latim consumere, coloca em série gastar, comer, destruir, dar cabo, arruinar, além de comungar (o padre, à missa), sentidos bastante presentes nas elaborações psicanalíticas sobre o tema.

Pudemos constatar esse desvelamento da consumição sob o consumismo nos extratos clínicos mencionados brevemente no decorrer do texto. Em um deles, a analisante se serve dos caixas-eletrônicos com funcionamento 24 horas como de um serviço de pronto-atendimento e os "barulhinhos" da máquina têm um efeito hipnótico sobre ela. No momento seguinte, ela é forçada à contabilização de uma dívida de proporções assustadoras, dívida que passa a lhe consumir a vida cotidiana. Em outro caso, a filha disputa com as quinquilharias, que no caso tomam a forma de sapatos, um lugar no desejo da mãe. Se, ainda no seu texto "A terceira", Lacan ([1974] 1980) observou que um sujeito pode tomar um automóvel como uma falsa mulher, isso nos permite assinalar a particularidade das parcerias com esses objetos, os gadgets, que não interpelam o sujeito quanto ao seu desejo, quanto ao seu amor e nem quanto ao seu gozo, parcerias nas quais ele acaba fazendo economia do laço social com o Outro.

\section{D) OS OBJETOS E A INVENÇÃO DE NOVOS MODOS DE NARRAR}

Se o mundo contemporâneo é regido pelas fabricações da ciência, o espaço no qual elas circulam está ocupado por "ondas hertzianas (ondas eletromagnéticas utilizadas em rádio transmissão) ou quaisquer outras" (Lacan, [1969-1970] 1992: 153), inapreensíveis no nível da percepção. $\mathrm{O}$ ar, a atmosfera contemporânea, estaria povoado pelas fabricaçôes da ciência em sua verdade formalizada. O jogo de encobrimento e revelação da verdade, da aletheia, dá lugar a um neologismo que permite a Lacan renomear esse espaço: a aletosfera. E ela, a aletosfera, estará povoada pela acoisa (lachose), pelas latusas, por esses pequenos objetos que estão à mostra "no pavimento de todas as esquinas, atrás de todas as vitrines" (Lacan, [1969-1970] 1992: 153). Na sua proliferação, na sua multiplicação, eles são feitos para causar o desejo e, isso, "na medida em que agora é a ciência que o governa" (Lacan, [1969-1970] 1992: 153).

Para finalizar, é interessante notar que lathouse rima com ventouse, isto é, que latusa rima com ventosa, portanto "há vento ali dentro, muito vento, o vento da voz humana” (Lacan, [1969-1970] 1992: 154). Assim, face às presenças hegemônicas 
do cientista e do capitalista, podemos insistir em que restará sempre o recurso de uma voz humana que se põe a inventar histórias ou mesmo a voz do poeta quando narra o modo como Ulisses enganou a antropofagia do Outro. À pergunta sobre seu nome próprio, ao responder "Meu nome é Ninguém”, o herói clássico se valeu de uma astúcia demonstrando-a em ato: disse seu nome, escondendo-o. A resposta não se fez esperar: "Ninguém, hei de comer-te!", disse o ciclope, anunciando, sem se dar conta, o seu próprio fracasso (Homero, [8bC] 2000). A sorte de Ulisses foi a de ter habitado um mundo onde a presença de um vazio no campo do sentido e das referências abriu à invenção. Já a antropofagia e o consumismo e/ou a consumição contemporânea parecem estar a nos exigir a invenção de novos modos de narrar. E então, quais serão as estórias que contaremos aos nossos descendentes?

\section{REFERÊNCIAS}

Abraham, K. (1924/1970). A influência do erotismo oral na formação do caráter. In: Teoria psicanalítica da libido. Sobre o caráter e o desenvolvimento da libido (pp. 161-173). Rio de Janeiro: Imago.

Bidaud, E. (1998). Anorexia mental, ascese, mistica. Rio de Janeiro: Companhia de Freud.

Freud, S. (1915/1974). Os instintos e suas vicissitudes. Obras completas, ESB, v. XIV. Rio de Janeiro: Imago.

Freud, S. (1916-1917/1974). Conferências introdutórias sobre a psicanálise (parte III). Obras completas, v. XVI. Rio de Janeiro: Imago.

Homero. (8bC/2000). Odisséia. Tradução de Manuel Odorico Mendes. São Paulo: Ars Poética / Editora da Universidade de São Paulo.

Lacan, J. (1959-1960/1988). O seminário, livro 7: a ética da psicanálise. Rio de Janeiro: Jorge Zahar Editor.

Lacan, J. (1960-1961/1992). O seminário, livro 8: a transferência. Rio de Janeiro: Jorge Zahar Editor.

Lacan, J. (1962-1963/2005). O seminário, livro 10: a angústia. Rio de Janeiro: Jorge Zahar Editor.

Lacan, J. (1964/1988). O seminário, livro 11: os quatro conceitos fundamentais da psicanálise. Rio de Janeiro: Jorge Zahar Editor.

Lacan, J. (1969-1970/1992). O seminário, livro 17: o avesso da psicanálise. Rio de Janeiro: Jorge Zahar Editor.

Lacan, J. (1972-1973/1982). O seminário, livro 20: mais, ainda. Rio de Janeiro: Jorge Zahar Editor. 
Lacan, J. (1972/1978). Du discours psychanalytique. In: Lacan in Itália (pp. 32-55). Milāo: La Salamandra.

Lacan, J. (1974/1980). La tercera. In: Actas de la Escuela Freudiana de Paris (pp. 159-186). Barcelona: Ediciones Petrel.

Lacan, J. (1974/1993). Televisão. Rio de Janeiro: Jorge Zahar Editor.

Rabinovich, D. (1989). Una clínica de la pulsión: las impulsiones. Buenos Aires: Manantial.

Soler, C. (1998). O sintoma na civilização. Curinga, 11, 164-174.

Recebido em 21 de julho de 2008 Aceito para publicação em 22 de abril de 2010 